\title{
Effects of murine recombinant interleukin 1 on synovial joints in mice: measurement of patellar cartilage metabolism and joint inflammation
}

\author{
A A J van de Loo, W B van den Berg
}

\begin{abstract}
Murine recombinant interleukin 1 was injected intra-articularly into mice. It induced a clear effect on patellar cartilage within 24 hours. A low dose of interleukin 1 (1 ng) elicited a significant reduction in $\left[{ }^{35} \mathrm{~S}\right]$ sulphate incorporation $(50 \%)$ into proteoglycans and an accelerated breakdown (twofold) of ${ }^{35} \mathrm{~S}$ prelabelled proteoglycan. Proteoglycan breakdown returned to normal rates $(\sim 10 \% /$ day $) 48$ hours after a single interleukin 1 injection. Recovery of proteoglycan synthesis was delayed by up to 72 hours, however, which implies that repair of the depleted cartilage matrix is retarded. Interleukin 1 induced only minor joint inflammation, too slight to be held responsible for the strong suppression of proteoglycan synthesis. Vehement joint inflammation was found after repeated interleukin 1 injections. The plasma extravasation and massive infiltration and exudation of leucocytes, predominantly polymorphonuclear leucocytes, were not a mere summation of single interleukin 1 effects, but point to interleukin 1 induced local hypersensitivity. The cartilage matrices of patella and femur were heavily depleted. Measurement of the extent of loss of ${ }^{35} \mathrm{~S}$ prelabelled proteoglycan and the prolonged inhibition of $\left[{ }^{35} \mathrm{~S}\right]$ sulphate incorporation indicate that both inhibition of proteoglycan synthesis and enhanced loss of proteoglycan contributed substantially to this depletion.
\end{abstract}

Interleukin 1 is a 17 kilodalton soluble unglycosylated protein, secreted by activated cells of mononuclear origin. Two forms have been described, interleukin $1 \alpha$ and interleukin $1 \beta$, which are related proteins that bind to the same receptor and show roughly the same biological effects. ${ }^{1-3}$ This ubiquitous mediator displays many inflammatory and immunoregulatory activities. $^{1-5}$ After systemic administration interleukin 1 gave rise, for example, to an acute phase response, enhanced immunoglobulin production, and protection against bacterial injury. ${ }^{6-10}$ Apart from systemic effects, related to high concentrations of circulating interleukin 1 during inflammatory processes, ${ }^{11}$ interleukin 1 may also play a more direct part in local inflammatory events. It has been shown that interleukin 1 injected into the skin attracted neutrophils, leading to microvascular injury. ${ }^{12-14}$ Moreover, interleukin 1 enhanced the binding of lymphocytes to endothelial cells and promoted chemotaxis of these cells. ${ }^{15-20}$ Recombinant interleukin 1 injected directly into rabbit knee joints induced only minor inflammation, ${ }^{21}$ but it was highly effective in causing an exacerbation of the arthritic process in a previously injured joint. $^{22}$ The important role of interleukin 1 in arthritis is further substantiated by the observation that it is produced by the arthritic synovium ${ }^{23} 24$ and it can be detected in substantial amounts in synovial fluids. ${ }^{25-29}$ Whether interleukin 1 is the predominant pathological messenger or only one of many effector cytokines in arthritis is still unknown.

In addition, interleukin 1 may contribute to connective tissue activation and cartilage destruction. In vitro studies have shown that interleukin 1 (catabolin) added to living explants of cartilage induces loss of matrix proteoglycans and inhibition of synthesis of proteoglycans. ${ }^{30-37}$ In vivo studies with purified interleukin 1 showed significant loss of proteoglycans and inhibition of proteoglycan synthesis after intraarticular injection, and the presence of clear joint inflammation. ${ }^{38-40}$ Recent studies with recombinant interleukin 1 disclosed only minor signs of inflammation. Nevertheless, proteoglycan loss was clearly shown and it was concluded that degradation of cartilage induced by interleukin 1 was unrelated to inflammation. ${ }^{21}{ }^{41}$ Effects on proteoglycan synthesis were not determined. We studied the impact of recombinant murine interleukin 1 after single and repeated injections in the murine knee joint. Special attention was paid to measurement of both the inflammation and two indices of cartilage destruction-proteoglycan loss and inhibition of proteoglycan synthesis.

\section{Materials and methods}

ANIMALS

C57b1/10 mice aged 8-10 weeks at the start of the experiments were used. They were fed a standard diet and tap water freely.

\section{CHEMICALS}

Recombinant interleukin $1 \alpha$ and interleukin $1 \beta$ were kindly supplied by Dr I G Otterness (Pfizer Central Research, Groton, CT). Biological activity was verified by a lymphocyte activating factor assay. The interleukin 1 gave 1 unit activity consistently in the $10-40 \mathrm{pg} / \mathrm{ml}$ range. Screening for endotoxin activity (Limulus assay) was negative up to a concentration of 100 $\mu \mathrm{g} / \mathrm{ml}$. The recombinant interleukin 1 preparation was stored at $-20^{\circ} \mathrm{C}$ and showed consistent lymphocyte activating factor activity over the period studied.

Zymosan A was obtained from Sigma (Sac- 
charomyces cerevisiae, No Z-4250). Zymosan (30. $\mathrm{mg}$ ) was dissolved in $1 \mathrm{ml}$ saline by heating up to $100^{\circ} \mathrm{C}$ twice, then sonicated to obtain a homogeneous suspension. Batches were stored at $-20^{\circ} \mathrm{C}$.

\section{LYMPHOCYTE ACTIVATING FACTOR ACTIVITY}

Murine thymocytes from mice, aged 6-7 weeks, were cultured for four days in the presence of 1 $\mu \mathrm{g} / \mathrm{ml}$ phytohaemagglutinin and various interleukin 1 concentrations. Thymocytes were cultured at a concentration of $10^{7} / \mathrm{ml}$ in $200 \mu \mathrm{l}$ wells, and $\left[{ }^{3} \mathrm{H}\right]$ thymidine was added $(37 \mathrm{kBq} /$ well) during the last day. One unit of lymphocyte activating factor activity was defined as the interleukin 1 concentration giving half the plateau of comitogenic thymocyte proliferation induced by interleukin 1 .

\section{INTRA-ARTICULAR INJECTIONS}

Recombinant interleukin 1 or zymosan was injected through the suprapatellar ligament into the left knee joint space. In experiments investigating the proteoglycan metabolism the contralateral joint received an equal volume $(6 \mu \mathrm{l})$ of saline. In the technetium uptake experiments only an incision into the skin was made in the contralateral knee. In these experiments a control group was included, in which saline was injected into the left knee joint. From the latter experiments it became clear that saline neither induced measurable joint inflammation nor influenced proteoglycan metabolism.

\section{${ }^{49 m}$ T $\mathrm{c}$ UPTAKE MEASUREMENTS}

Joint inflammation was determined by measurements of ${ }^{99 \mathrm{~m}} \mathrm{Tc}$ pertechnetate uptake in the knee joints. ${ }^{42}$ Briefly, animals were sedated by intraperitoneal administration of $4 \cdot 5 \%$ chloral hydrate, $0.1 \mathrm{ml} / 10 \mathrm{mg}$ of body weight. Approximately $370 \mathrm{kBq}{ }^{99 \mathrm{~m}} \mathrm{Tc}$ in $0.2 \mathrm{ml}$ saline was injected subcutaneously in the neck region. After 15 minutes the accumulation of isotope in the knee, owing to increased blood flow and tissue swelling, was determined by external gamma counting. The severity of inflammation was expressed as the ratio of the ${ }^{99 \mathrm{~m}} \mathrm{Tc}$ uptake in the left knee joint (zymosan or interleukin 1 injected) over that in the right knee joint.

\section{BREAKDOWN OF $\left[{ }^{35}\right.$ S $]$ PROTEOGLYCANS}

To study in vivo degradation of patellar cartilage proteoglycans were prelabelled with $\mathrm{Na}_{2}{ }^{35} \mathrm{SO}_{4}$. $\left.{ }^{35} \mathrm{~S}\right]$ Sulphate $(1 \cdot 85-3 \cdot 7 \mathrm{MBq})$ was injected intraperitoneally 24 hours before intra-articular injection of interleukin 1 , and patellae were isolated at various times thereafter. Before intra-articular injection $(\mathrm{t}=0)$ one group of six mice was killed and the ${ }^{35} \mathrm{~S}$ content was measured. Breakdown of proteoglycans was expressed as the loss of $\left[{ }^{35} \mathrm{~S}\right]$ sulphate compared with the ${ }^{35} \mathrm{~S}$ content of control patellae taken at $\mathbf{t}=\mathbf{0}$.

SYNTHESIS OF PATELLAR PROTEOGLYCANS

Proteoglycan synthesis was measured ex vivo.
Patellae were dissected, leaving a minimal area of non-cartilaginous tissue surrounding the cartilage. The patellae (five to six specimens) were placed in $2 \mathrm{ml}$ of incubation medium consisting of RPMI-HEPES ( $N$-2-hydroxyethylpiperazine- $N$ '-2-ethanesulphonic acid; Flow Laboratories, Irvine, Scotland) with added penicillin (100 units/ml), streptomycin (100 $\mu \mathrm{g} / \mathrm{ml})$, and L-glutamine $(2 \mathrm{mmol} / \mathrm{l})$ and $74 \mathrm{kBq}$ ${ }^{35} \mathrm{SO}_{4}$. Labelling was continued for three hours. At the end of the incubation period the patellae were fixed overnight in $10 \%$ formalin and decalcified in formic acid (5\%) for four hours. The patella could then easily be punched out of the adjacent tissue and was dissolved in $0.5 \mathrm{ml}$ Luma solve (Hicol, Oud-Beijerland, The Netherlands) at $60^{\circ} \mathrm{C}$ for four hours. The ${ }^{35} \mathrm{~S}$ content of each patella, which is a reliable measure of the $\left[{ }^{35} \mathrm{~S}\right]$ glycosaminoglycan content, ${ }^{43}$ was measured by liquid scintillation counting.

\section{IODINATION OF INTERLEUKIN 1}

About $25 \mu \mathrm{g}$ interleukin $1 \alpha$ was radiolabelled with ${ }^{125}$ I (Amersham International, Buckinghamshire, UK) by the Bolton and Hunter method. The iodinated protein was smaller than 17 kilodaltons as shown with sodium dodecyl sulphate-polyacrylamide gel electrophoresis, and more than $90 \%$ of the radiolabelled preparation could be precipitated with goat antimouse interleukin $1 \alpha$ antisera. The labelled preparation also retained full biological activity.

\section{INTERLEUKIN 1 RETENTION MEASUREMENTS}

${ }^{125}$ I labelled interleukin 1 (800 units) was injected into the right knee joint and saline into the left knee joint. At various hours thereafter the ${ }^{125}$ I radioactivity of both knees was measured by external gamma counting. Values for the right knee were corrected according to the value for the left knee, which represents background activity. Retention was expressed as a percentage of the initial count rate measured immediately after $\left[{ }^{125} \mathrm{I}\right]$ interleukin 1 injection. In addition, quantitative measurements were made on dissected patellae.

\section{AUTORADIOGRAPHY}

Dry deparaffinised tissue sections of whole patellae were covered by a photographic K5 emulsion (Ilford, Basildon, Essex, UK) and exposed for three to five weeks. After this period the slides were developed and stained with haematoxylin and eosin.

\section{HISTOLOGY OF KNEE JOINTS}

Histological scoring of the inflamed knees was carried out after dissection and processing. ${ }^{44}$ Standard frontal sections $(6 \mu \mathrm{m})$ were prepared and stained with haematoxylin and eosin, Giemsa stain, or with safranin $O$, which enables identification of neutrophils and eosinophils. Eosinophils were not seen after interleukin 1 injection. The arthritic score was determined by grading the infiltrate and the exudate from 0 
to +++ , where $0=$ no change, and $+++=$ large numbers of cells. The scoring of cartilage depletion was done on safranin $\mathrm{O}$ sections and depletion was graded from 0 to +++ in accordance with the degree of loss of staining in the superficial, metabolically active cartilage layer.

\section{Results}

SUPPRESSION OF THE PROTEOGLYCAN SYNTHESIS Interleukin 1 induced marked changes in the metabolism of cartilage in vivo. The suppression of proteoglycan synthesis in patellar cartilage 24 hours after intra-articular injection was dependent on dose (fig 1). There was considerable inhibition of proteoglycan synthesis at low doses (3 U) of interleukin 1 , and $30 \mathrm{U}$ interleukin 1 (about $1 \mathrm{ng}$ ) was sufficient to decrease the proteoglycan synthesis to $60 \%$ of normal. Recombinant murine interleukin $1 \beta$ was as potent as interleukin $1 \alpha$ in the suppression of proteoglycan synthesis (table 1 ). The in vivo potency of interleukin 1 was further shown by the rapid appearance of the interleukin 1 effect. With 30 $\mathrm{U}$ of interleukin 1 the proteoglycan synthesis showed maximal suppression at 24 hours, which remained high for up to 48 hours and declined thereafter (fig 2). When a high dose of interleukin $1(300 \mathrm{U})$ was used the suppression was

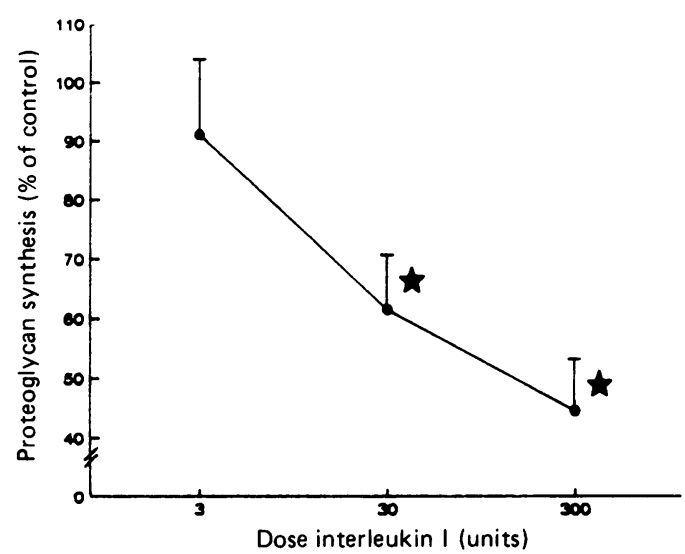

Figure 1: Proteoglycan synthesis suppression by interleukin 1. Interleukin I a was intra-articularly injected into mice; the contralateral knee joint received saline. After 24 hours the patellae were dissected and cultured in tissue medium supplemented with $\left[{ }^{35} S\right]$ sulphate for three hours. Proteoglycan synthesis was expressed as a percentage of control ${ }^{35} S$ incorporation in the contralateral knee joint. The values represents the mean (SD) of at least four experiments consisting of six animals each. Significant differences with respect to saline are indicated by $\star(p<0 \cdot 001$, Student's $t$ test) and calculated from the cpm values.

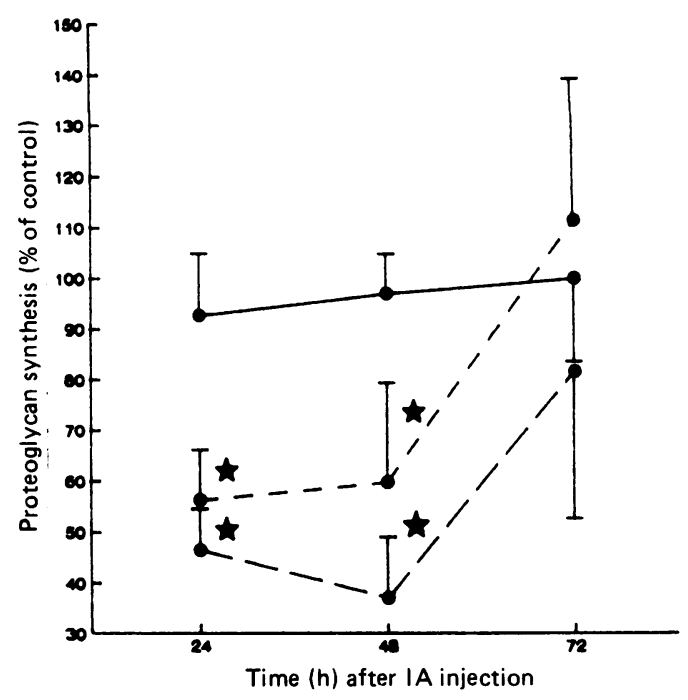

Figure 2: Time course of proteoglycan synthesis suppression by interleukin 1. Proteoglycan synthesis was measured by $\left[{ }^{35} S\right]$ sulphate incorporation (see fig 1) at various days after (-) 3 units, (- - ) 30 units, or (_ _ - 300 units of interleukin $1 \alpha$ injection. Each value represents the mean of at least three experiments consisting of six animals. Significant differences with respect to saline are indicated by $\star$ $(p<0.001$, Student's t test.

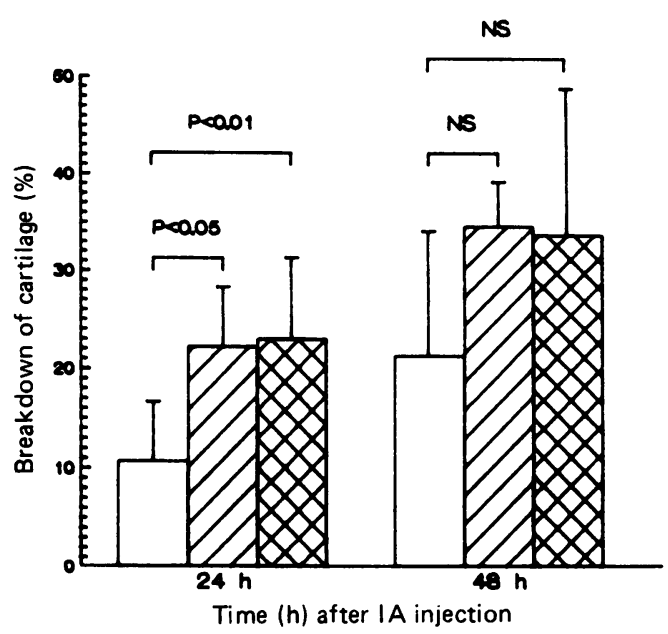

Figure 3: Enhanced breakdown of patellar proteoglycan by interleukin I $\alpha$. Animals received $1 \cdot 85 \mathrm{MBq}\left[{ }^{35} \mathrm{~S}\right]$ sulphate intraperitoneally 24 hours before intra-articular interleukin I administration. The ${ }^{35} S$ loss from patellae at 24 and 48 hours was expressed as a percentage of the ${ }^{35} S$ content at $t=0(235$ (50) cpm). The bar of 30 units interleukin 1 represents the mean of three experiments and the 300 unit bars the mean of five experiments with six animals each.

$\nabla Z=30 \mathrm{U}$ interleukin 1; $\square \triangle \square=300 \mathrm{U}$

interleukin 1; $\square=$ saline.

Table 1: Comparison of effects of interleukin $I \alpha(I L I \alpha)$ and interleukin $I \beta$ (ILI/3) on patellar cartilage homeostasis

\begin{tabular}{|c|c|c|c|c|c|c|c|c|}
\hline \multirow{3}{*}{$\begin{array}{l}\overline{\text { Dose }} \\
(U)\end{array}$} & \multicolumn{4}{|c|}{ Synthesis at $t=24 h$} & \multicolumn{4}{|c|}{ Breakdown and loss of $I^{35} S /$ sulphatet } \\
\hline & \multicolumn{2}{|l|}{ cpm/patella } & \multicolumn{2}{|c|}{$\%$ Of saline } & \multicolumn{2}{|c|}{$t=24 h$} & \multicolumn{2}{|c|}{$t=48 h$} \\
\hline & ILla & $I L I \beta$ & ILIK & ILIF & ILla & ILIR; & ILla & ILIP \\
\hline 0 & $626(41)$ & $616(76)$ & 100 & 100 & 11 & 15 & 21 & 30 \\
\hline 30 & $470(95)^{*}$ & $555(75)$ & 75 & 90 & - & - & - & $=$ \\
\hline 300 & $\begin{array}{l}290(22) \\
242(20) * * *\end{array}$ & $\begin{array}{l}269(18) \\
270(25) * *\end{array}$ & $\begin{array}{l}47 \\
38\end{array}$ & $\begin{array}{l}44 \\
43\end{array}$ & $\overline{27}$ & $\overline{22}$ & $\overline{31}$ & $\overline{37}$ \\
\hline
\end{tabular}

The proteoglycan synthesis after interleukin 1 injection was significantly suppressed- $p<0.05 ; p<0.001-$ as calculated with Student's $t$ test. This representative experiment was carried out with groups of six mice each. Values are mean (SD). Student's $t$ test. This representative experiment was carried out with groups of six mice each. Values are mean (SD).
tThe ${ }^{35} \mathrm{~S}$ content was determined at 24 and 48 hours and the loss of label was expressed as a percentage of the ${ }^{35} \mathrm{~S}$ content at $t=0$ (15t (25) $\mathrm{cpm} /$ patella) 
greater at 48 hours than with lower doses, though not reaching statistical significance compared with 24 hours; suppression was still observed at 72 hours. Restoration of proteoglycan synthesis was inconsistent. The mean value $(75 \%$ of normal proteoglycan synthesis) was an average that included animals which showed full recovery and some animals still with full suppression. Although a lower dose of interleukin 1 (30 U) induced the same suppression at 24 and 48 hours as $300 \mathrm{U}$, there was complete recovery of proteoglycan synthesis at 72 hours and sometimes enhanced proteoglycan synthesis. An overshoot to enhanced synthesis was more marked at later times (data not shown), and this phenomenon contributes to accelerated recovery of the depleted matrix.

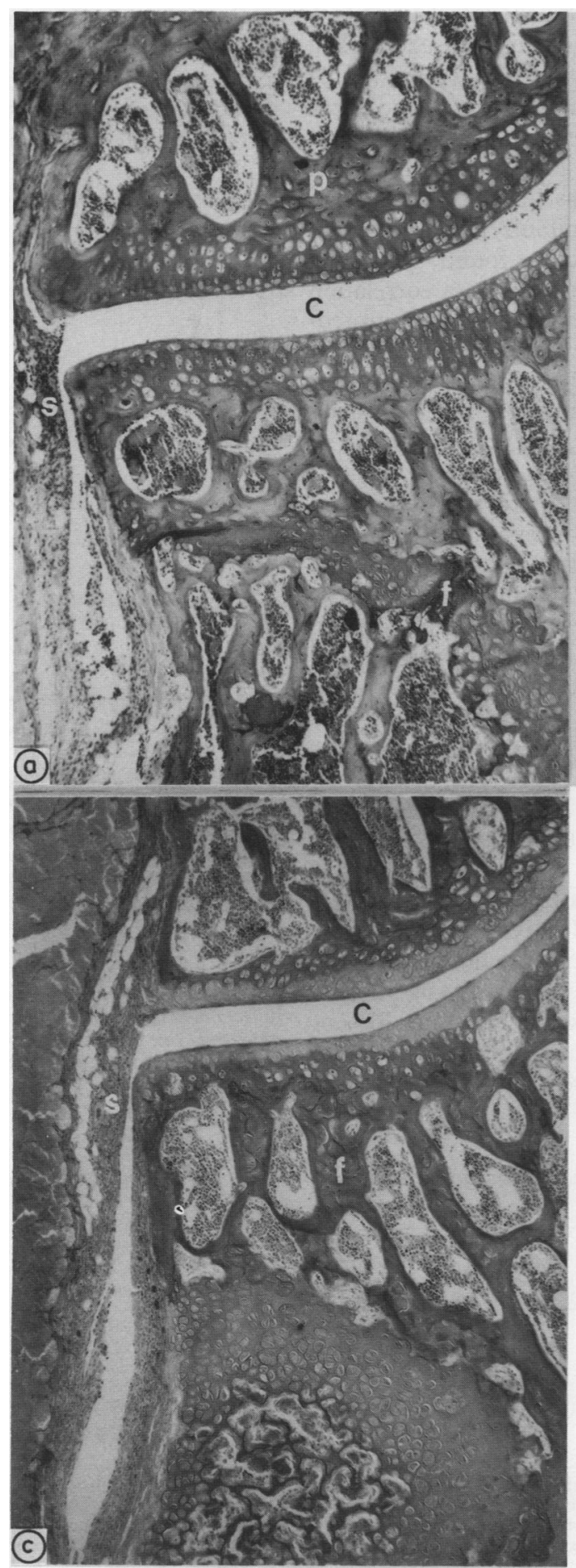

ACCELERATED BREAKDOWN OF PATELLAR

CARTILAGE

Coincident with significant suppression of proteoglycan synthesis, interleukin 1 induced an accelerated breakdown of prelabelled proteoglycans (fig 3). A low dose of interleukin $1 \alpha(30$ $\mathrm{U})$ was almost as effective as the higher dose (300 U). This sensitivity of patellar cartilage to interleukin 1 had already been seen in the suppression of proteoglycan synthesis. The basal proteoglycan breakdown in control patellae was $10 \cdot 7(\mathrm{SD} 6 \cdot 0) \%(\mathrm{n}=9)$ as measured by loss of $\left[{ }^{35} \mathrm{~S}\right]$ sulphate between 0 and 24 hours. In the presence of interleukin $1 \alpha(300 \mathrm{U})$ the breakdown was $23 \cdot 0(9 \cdot 1) \%(n=6)$ during the first 24 hours after injection. This means that interleukin 1 accelerated the proteoglycan breakdown rate

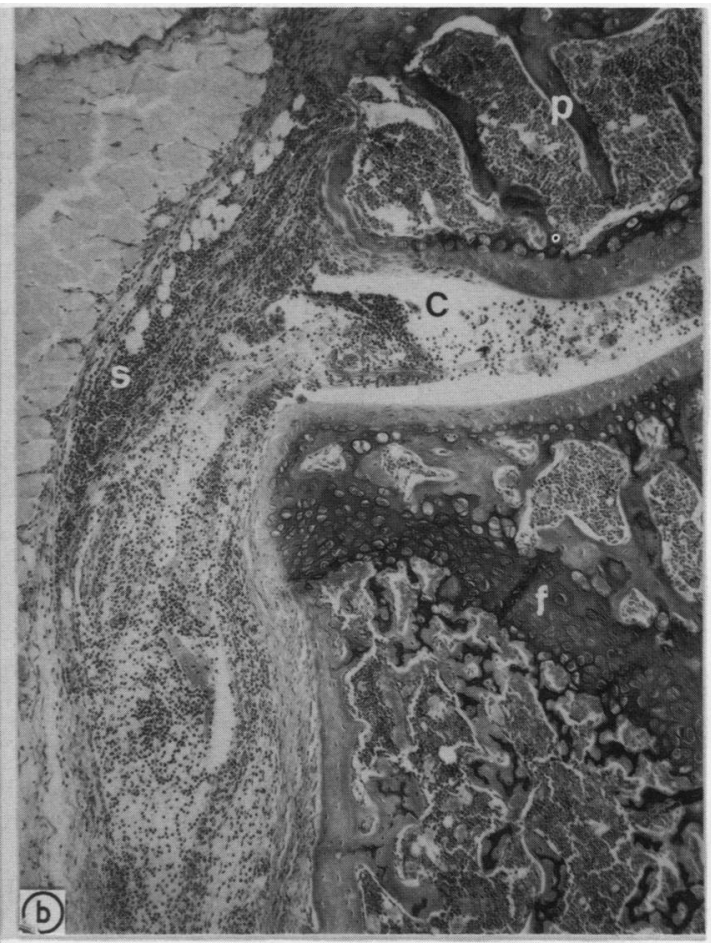

Figure 4: Tissue sections of interleukin 1 injected knee joints stained with safranin 0. Detailed representative histology of mice from the experiment described in table 3. (a) High magnification of joint cavity 24 hours after a single $(300 \mathrm{U})$ interleukin 1 injection; note the minor infiltration of cells into synovial membrane $(s)$. (b) Foint section six hours after the last of triple interleukin 1 injections; note the dense accumulation of neutrophils in synovial membrane and joint cavity (c) and loss of cartilage matrix of femur $(f)$ and patella (p). (c) Knee joint 48 hours after the last of three interleukin I injections; note the disappearance of the inflammatory cells and continued depletion of cartilage matrix. 
twofold. Further accelerated loss of proteoglycans between 24 and 48 hours after interleukin 1 injection was limited. Interleukin $1 \beta$ also induced significant breakdown, but seemed less potent than interleukin $1 \alpha$ in a comparative experiment (table 1). Histologically, in sections of whole knee joints, no clear cut loss of cartilage matrix could be seen 24 hours after a single interleukin 1 injection (fig 4).

\section{SUPPRESSION OF PROTEOGLYCAN SYNTHESIS BY INTERLEUKIN \& AND THE EFFECT OF INFLAMMATION}

To investigate whether the effect of interleukin 1 on the articular cartilage was related to its potential to induce joint inflammation we compared the effect of various doses of the arthritogen zymosan and recombinant interleukin 1 . A high dose of zymosan $(60 \mu \mathrm{g})$ caused marked suppression of proteoglycan synthesis (46\%) 24 hours after intra-articular injection, and technetium uptake measurements, reflecting joint inflammation, were considerably raised. When the dose of zymosan was lowered, less severe inflammation and concomitantly less suppression of proteoglycan synthesis was found, indicating that in this dose range there was a correlation between inflammation and inhibition of proteoglycan synthesis. A dose of $1.8 \mu \mathrm{g}$ zymosan still induced significant joint swelling ( $\mathrm{T} c$ uptake) but the effect on proteoglycan synthesis was no longer seen. In contrast, interleukin $1 \alpha$ in the dose range studied did not induce enhanced technetium uptake, but there was a marked inhibition of proteoglycan synthesis (table 2). Histology showed that after 24 hours there was only minor infiltration of polymorphonuclear leucocytes into the synovial membrane (fig 4).

In conclusion, the inhibition of proteoglycan synthesis by interleukin 1 must be due to a direct effect on cartilage and was not secondary to inflammation induced by interleukin 1 .

\section{INTERLEUKIN $1 \alpha$ RETENTION IN MURINE KNEE} JOINT

The iodinated interleukin 1 (Bolton and Hunter) retained its full biological activity and molecular character. There was a poor retention of $\left[{ }^{125} \mathrm{I}\right]$ interleukin 1 in the naive knee joint (fig 5). One hour after $\left[{ }^{125} \mathrm{I}\right]$ interleukin 1 injection $30 \%$ of interleukin 1 was retained, and at six hours retention fell below $10 \%$. The penetration of interleukin 1 into the patella was poor. Autoradiology carried out shortly after injection showed no distinct labelling of the cartilage compared with the joint cavity. At six hours after $\left[{ }^{125} \mathrm{I}\right]$ interleukin 1 injection only $0.02 \mathrm{U}$ $\left.{ }^{125} I\right]$ interleukin 1 was retrieved in the isolated patella and autoradiography showed that interleukin 1 was faintly dispersed in the patellar cartilage matrix. Distinct association with chondrocytes was never found.

JOINT INFLAMMATION AND MATRIX DEPLETION AFTER REPEATED INTERLEUKIN 1 INJECTIONS

Although a single interleukin 1 (300 U) injection did not result in significant joint swelling, interleukin $1 \alpha$ did cause minor inflammatory changes, like scant polymorphonuclear leucocyte influx in the synovial membranes and the joint cavity at six hours with a decline in cell influx at 24 hours. When interleukin 1 was repeatedly injected every two days, however, clear cut joint inflammation was measurable at six hours ( $\mathrm{Tc}$

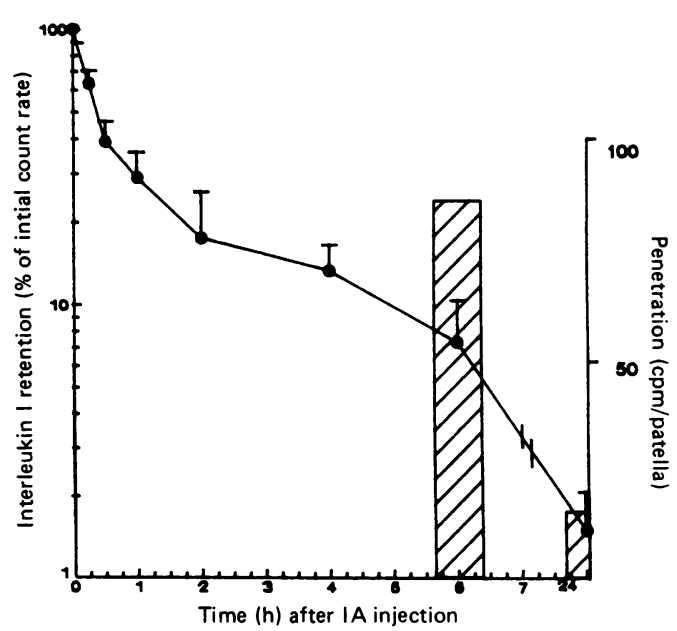

Figure 5: Interleukin I $\alpha$ retention in murine knee joint and penetration into patellar cartilage. Interleukin 1 iodinated by the method described by Bolton and Hunter remained biologically active as based on costimulation of thymocyte proliferation. In naive knee joints 800 units of

${ }^{125}$ I interleukin 1 (about $20 \mathrm{ng}$ or $3 \times 10^{6} \mathrm{cpm}$ ) was injected. The retention of $\left[^{125}\right.$ I] interleukin 1 in the knee joint was measured by external gamma counting. [ ${ }^{125}$ I] interleukin I content in dissected patellae was an estimation of the interleukin 1 penetration into cartilage. Six hours after injection $80 \mathrm{cpm}$ (about 0.02 units interleukin 1) could be retrieved. The proteoglycan synthesis in patellar cartilage 24 hours after injection of $\left[^{125} I\right]$ interleukin 1 was suppressed $(41 \%)$.

Table 2: Comparison of the effect of zymosan and interleukin $1 \alpha$ on joint inflammation and proteoglycan synthesis. Values are given as means ( $S D)$

\begin{tabular}{|c|c|c|c|c|}
\hline \multirow[t]{2}{*}{ Substance } & \multirow{2}{*}{$\begin{array}{l}\text { Dose } \\
\text { (intra-articular) }\end{array}$} & \multirow{2}{*}{$\begin{array}{l}\text { Inflammation } \\
{ }_{9 y_{m}} \text { Tc ratiof }\end{array}$} & \multicolumn{2}{|c|}{ Proteoglycan synthesisf } \\
\hline & & & cpm/patella & $\%$ Of control \\
\hline $\begin{array}{l}\text { Saline } \\
\text { Zymosan ( } \mu \mathrm{g} / \text { knee })\end{array}$ & $\begin{array}{r}- \\
1.8 \\
6 \cdot 0 \\
18 \cdot 0 \\
60 \cdot 0 \\
30 \\
300\end{array}$ & $\begin{array}{l}1.09(0.08) \\
1.23(0.08) \\
1.32(0.09)^{*} \\
1.41(0.10)^{*} \\
1.80(0.07)^{*} \\
1.04(0.05) \\
1.02(0.05)\end{array}$ & $\begin{array}{l}1303(245) \\
1087(106) \\
940(109) \\
845(99)^{*} \\
675(135)^{*} \\
732(51)^{*} \\
401(31)^{*}\end{array}$ & $\begin{array}{r}109 \\
99 \\
76 \\
62 \\
54 \\
64 \\
35\end{array}$ \\
\hline
\end{tabular}

tJoint swelling was detected by enhanced ${ }^{\% 9 \mathrm{~m}} \mathrm{~T} c$ pertechnetate uptake as measured by external gamma counting. This was expressed as a ratio of the technetium uptake in the inflamed knee over that in the contralateral knee of the same animal.

$\ddagger$ Patellae were dissected and the proteoglycan synthesis was determined by $\left[{ }^{35} S\right]$ sulphate incorporation. In the untreated contralateral patellae the ${ }^{35} \mathrm{~S}$ incorporation was stated as $100 \%$. Significant differences- ${ }^{*} \mathrm{p}<0.001$ - with respect to the contralateral knee were calculated with Student's $t$ test. 
Table 3: The inflammatory response of single and repeated interleukin $l a$ injections and the effects on cartilage matrix

\begin{tabular}{|c|c|c|c|c|c|c|}
\hline \multirow[t]{2}{*}{ Variable } & \multicolumn{3}{|c|}{ Single ILIt injection } & \multicolumn{3}{|c|}{ Triple ILI injections } \\
\hline & $6 h$ & $24 h$ & $48 h$ & $6 h$ & $24 h$ & $48 h$ \\
\hline $\begin{array}{l}\text { Infiltration } \\
\text { Exudation } \\
\text { Proteoglycan depletion }\end{array}$ & $\begin{array}{l}\text { ND } \\
\text { ND } \\
\text { ND }\end{array}$ & $\begin{array}{l}+ \\
\pm \\
0\end{array}$ & $\begin{array}{l} \pm \\
0 \\
0\end{array}$ & $\begin{array}{r}+++ \\
+ \\
++\end{array}$ & $\begin{array}{r}++ \\
\pm \\
++\end{array}$ & $\begin{array}{r} \pm \\
0 \\
+++\end{array}$ \\
\hline${ }^{4} \mathrm{~m} \cdot \mathrm{Tc}$ ratio $(\operatorname{mean}(\mathrm{SD}))$ & $1.03(0.09)$ & $1.02(0.05)$ & ND & $1.22(0.06)=$ & $1.03(0.06)$ & ND \\
\hline
\end{tabular}

Representative experiment in which single and triple (three times on alternate days) interleukin 1 injections were compared for their inflammatory effect, six to 48 hours after the last injection. The joint sections were scored on: infiltration of leucocytes into the synovial inflator membrane, exudation of polymorphonuclear cells into the joint cavity, and the proteoglycan depletion of cartilage matrix. Histological changes were arbitrarily represented as $0=$ no changes, $t=$ slight, $+=$ moderate, $++=$ marked, $+++=$ strong. Joint swelling was
expressed by an enhanced ratio of ${ }^{9 m} \mathrm{~T} c$ pertechnetate uptake, and significant differences- ${ }^{*} \mathrm{p}<0 \cdot 001$-were calculated by Student's $t$

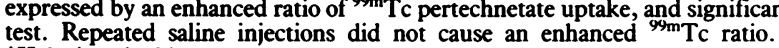
†IL $1=$ interleukin 1 .

Table 4: Effects of single and repeated interleukin $1 \alpha$ injections on patellar proteoglycan metabolism

\begin{tabular}{|c|c|c|c|c|c|c|c|}
\hline \multirow[t]{2}{*}{ Variable } & \multirow[t]{2}{*}{ Substance } & \multicolumn{3}{|c|}{ cpm/patellat } & \multicolumn{3}{|c|}{$\%$ Of control } \\
\hline & & $O h$ & $24 h$ & $120 h$ & $O h$ & $24 h$ & $120 h$ \\
\hline Breakdown & $\begin{array}{l}\text { Saline } \\
\text { Interleukin } 1\end{array}$ & $380(156)$ & $\begin{array}{ll}339 & (82) \\
311 & (92)\end{array}$ & $\begin{array}{ll}240 & (44) \\
170 & (45)\end{array}$ & 100 & $\begin{array}{l}89 \\
82\end{array}$ & $\begin{array}{l}63 \\
45\end{array}$ \\
\hline Synthesis & $\begin{array}{l}\text { Saline } \\
\text { Interleukin 1 }\end{array}$ & ND & $\begin{array}{c}1195(101) \\
421(35)^{*}\end{array}$ & $\begin{array}{c}1062(145) \\
563(78)^{*}\end{array}$ & - & $\begin{array}{r}100 \\
36\end{array}$ & $\begin{array}{r}100 \\
53\end{array}$ \\
\hline
\end{tabular}

Representative experiment in which the effect on proteoglycan metabolism was compared at 24 hours after a single injection or triple injections $(120 \mathrm{~h})$ of saline or interleukin $1(300 \mathrm{U})$. Breakdown of patellar cartilage was measured as loss of ${ }^{35} \mathrm{~S}$ ]sulphate and expressed relative to the ${ }^{35} S$ content at $t=0$. Proteoglycan synthesis of patellae was measured as the amount of $\left[{ }^{35} S\right]$ sulphate incorporated. Significant differences-* ${ }^{*}<0.001$ - with respect to saline were calculated by Student's $t$ test.

†Values are means (SD).

uptake values in table 3). Histological observations showed major infiltration of polymorphonuclear leucocytes into the synovium and an exudate in the joint cavity, which persisted for up to 24 hours after the last injection and slowly declined thereafter.

Apart from infiltration of inflammatory cells, repeated injections of interleukin 1 resulted in impressive proteoglycan depletion in the articular cartilage surface layers (table 3 ). This depletion was even enhanced at 48 hours after the last injection. It might be the result of both the accelerated cumulative breakdown (18\%, table 4) and the insufficient resynthesis of proteoglycan (persistent inhibition, table 4). Although the cartilage matrix was heavily depleted of proteoglycans, the chondrocytes were still alive. No other dramatic histological disturbances in the articular components, such as bony changes, synovium haemorrhage, or cartilage cracks and loss of structure, were seen (fig 4). Proteoglycans were fully restored to the matrices seven days after withholding interleukin 1 , indicating that the interleukin 1 effects were not related to mere toxicity. Repeated interleukin 1 injections into the knee joint prolonged the interleukin 1 induced disturbance of the cartilage metabolism, suggesting that prolonged exposure to interleukin 1 during chronic joint inflammation may ultimately be responsible for the cartilage damage so typical of some forms of chronic arthritis.

\section{Discussion}

Our observations on the effects of recombinant interleukin 1 show two distinct alterations in synovial joints: $(a)$ induction of granulocyte accumulation in the joint and $(b)$ disturbance of the cartilage metabolism.
A single injection of interleukin 1 was only slightly inflammatory: it induced no enhanced plasma extravasation (tables 2 and 3 ) at 24 hours and only minor infiltration in the synovial membrane and exudation into the joint cavity, predominantly polymorphonuclear leucocytes (table 3, fig 4). It is known that interleukin 1 stimulates vascular endothelial cells to express a neutrophilCD18 antigen. This antigen facilitated the adhesiveness of neutrophils. ${ }^{13} 45$ Although new protein synthesis was required for this, the accumulation of neutrophils peaked at four hours but had subsided by 24 hours. ${ }^{13}$ 15 Even when we injected high doses of interleukin 1 (up to $800 \mathrm{U}$ ) still only minor inflammation could be observed at four to six hours (data not shown). Signs resembling experimental arthritis, like synovitis and severe cartilage matrix depletion, were only seen after repeated interleukin 1 injections; these signs were probably related to rapid interleukin 1 clearance from the joint (fig 5). The massive infiltration and major exudation of leucocytes after triple interleukin 1 injections were not a mere summation of the effects of each interleukin 1 injection. A local hypersensitivity for interleukin 1 as seen in the interleukin 1 induced local Shwartzman reaction in rabbit skin might be postulated. ${ }^{46} 47$ Similar interleukin 1 hyperreactivity was also shown in arthritic flares of joints previously injured with bacterial cell wall preparations, ${ }^{22}$ and we have recently shown that interleukin 1 causes flares of smouldering zymosan or antigen induced arthritis in mice. ${ }^{48}$ In addition, the onset of type II collagen induced arthritis in mice was enhanced by continuous administration of interleukin 1.49

The question arises whether inflammation was at least partially responsible for interleukin 1 induced cartilage depletion. We have shown 
that suppression of the proteoglycan synthesis induced by one single interleukin 1 injection was not caused by continuing inflammation. Compared with zymosan, interleukin 1 induced slight inflammation, too little to promote strong inhibition of proteoglycan synthesis (table 2). The suppression of proteoglycan synthesis after repeated interleukin 1 injections did not significantly differ from that after a single injection. Although significant inflammation was found after repeated interleukin 1 injections, it seems unlikely that the cumulative loss of $\left[{ }^{35} \mathrm{~S}\right]$ proteoglycan was related to this. The overall loss was $18 \%$ (table 4 ) and might well be explained by triple interleukin 1 insults, each resulting in $7-8 \%\left[{ }^{35}\right.$ S]proteoglycan degradation. Recent studies from Pettipher et al also provided evidence indicating a minor role for the inflammatory exudate in proteoglycan degradation. ${ }^{21}$ Proteoglycan loss from cartilage induced by interleukin 1 was unimpaired in neutropenic animals, ${ }^{41}$ and pronounced proteoglycan degradation was still found during antigen induced arthritis in neutropenic rabbits. ${ }^{41}$ Earlier studies in inflamed air pouches have pointed to the incompetence of an acute inflammatory exudate in cartilage breakdown. ${ }^{50}$ It may even be postulated that neutrophils prevent interleukin 1 effects as they contain a specific interleukin 1 inhibitor. ${ }^{51} 52$

The marked depletion of cartilage matrix after repeated interleukin 1 injections as shown by histology (fig 4) is probably the final result of both cumulative breakdown of proteoglycan (18\%, table 4) and prolonged suppression of proteoglycan synthesis $(50 \%$, table 4$)$. At day 1 after a single interleukin 1 injection about $10 \%$ proteoglycan depletion was found, and the lack of clear-cut proteoglycan loss on histological sections taken at that time (fig 4) indicates that this degree of depletion is beyond the detection limit. The marked depletion after repeated interleukin 1 injections must therefore reflect a much higher degree of proteoglycan depletion and this may only be explained by a considerable lack of sufficient resynthesis of new proteoglycan. Kinetic studies on this subject are in progress. Earlier studies with purified interleukin 1 preparations given once a day yielded high degrees of proteoglycan depletion, ${ }^{39} 40$ but the possibility that this was caused by other mediators present in the interleukin 1 preparation cannot be excluded. Moreover, in those studies the recovery was also very poor during the days after interleukin 1 exposure, ${ }^{39} 40$ in sharp contrast with the full recovery of the matrix seen with recombinant interleukin 1 in rabbits ${ }^{41}$ and in mice in this study. Five days after the last of the triple interleukin 1 injections inflammation was absent and cartilage was again heavily stainable with safranin $O$. At that stage an overshoot to enhanced proteoglycan synthesis was evident (data not shown).

The most outstanding action of interleukin 1 in vivo was its impressive longlasting inhibition of proteoglycan synthesis. This inhibition was not related to toxicity as full recovery was seen later. As stated above this inhibition contributes to proteoglycan depletion in the metabolically active murine cartilage matrix. It remains to be seen whether the inhibition of proteoglycan synthesis contributes in a similar degree to matrix depletion in older animals or in other species as it is obvious that it depends on turnover rates. Preliminary studies in our laboratory show that interleukin 1 induced even more prolonged inhibition of proteoglycan synthesis in the cartilage of old mice (18 months).

A recent study with isolated chondrocytes showed the onset of interleukin 1 induced suppression of proteoglycan synthesis six hours after first exposure and complete recovery to normal synthesis was found 48 hours after withholding interleukin $1,{ }^{53}$ effects in agreement with our in vivo results.

We found a comparable degree of suppression of proteoglycan synthesis and breakdown with recombinant interleukin $1 \alpha$ and $\beta$ (table 2); this is consistent with other studies. The effects of interleukin 1 on rabbit chondrocytes (prostaglandin $\mathrm{E}_{2}$ synthesis, phospholipase $\mathrm{A}_{2}$ secretion, neutral protease release) or on human chondrocytes (caseinase secretion, prostaglandin $\mathrm{E}_{2}$ production) or on cartilage resorption in explants show that both interleukin 1 species are almost equally potent. ${ }^{54-57}$ This is not surprising because chondrocytes possess a common class of receptors for interleukin $1 \alpha$ and $\beta$, with similar affinity. ${ }^{58}$ The overall effect of interleukin 1 on cartilage was dramatic: a joint suppression of proteoglycan synthesis and enhancement of proteoglycan breakdown, which amplifies matrix depletion. Both phenomena are clearly seen in experimental arthritis models and interleukin 1 seems a likely cause of both effects. The follow up of interleukin 1 studies may elucidate the exact role of interleukin 1 in various forms of arthritis.

1 Dinarello C A. Interleukin-1. Rev Infect Dis 1984; 6: 51-95.

2 Le J, Vilcek J. Biology of disease. Tumor necrosis factor and interleukin 1: cytokines with multiple overlapping

3 Oppenheim J J, Kovacs E J, Matsushima K, Durum S K. There is more than one interleukin 1. Immunology Today 1986; 7: 45-56.

4 Mizel S B. Interleukin 1 and T-cell activation. Immunology Today 1987; 8: 330-2.

5 Oppenheim J J, Lew W, Akahoshi T, Matsushima K, Neta $R$. Aspects of cytokine induced modulation of immunity and inflammation with emphasis on interleukin 1. Arzneimittelforschung 1988; 38: 461-5.

6 Dinarello $\mathrm{C} \mathrm{A}$. Interleukin-1 and the pathogenesis of the acute-phase response. $N$ Engl f Med 1984; 311: 1413-8.

7 Kampschmidt R F. Leukocytic endogenous mediator/endogenous pyrogen. In: Powanda M C, Canonico P G, eds. genous pyrogen. In: Powanda M C, Canonico P G, eds.
Infection: the physiologic and metabolic responses of the host. Infection: the physiologic and metabolic

8 Staruch M J, Wood D D. The adjuvanticity of interleukin 1 in vivo. $\mathcal{F}$ Immunol 1983; 130: 2191-4.

9 Gladue R, Girard A, Newborg $M$. Enhanced antibacterial resistance in neutropenic mice treated with human recombinant interleukin-1 beta. Agents Actions 1988; 24: 130-6.

10 Ozaki Y, Ohashi T, Minami A, Nakamura S I. Enhanced resistance of mice to bacterial infection induced by recombinant human interleukin-1 $\alpha$. Infect Immun 1987; 55: 1436-40.

11 Moldawer L L, Gelin J, Schersten T, Lundholm K G. Circulating interleukin $\mathrm{I}$ and tumor necrosis factor during inflammation. Am J Physiol 1987; 22: R922-8.

12 Cybulsky M I, McComb D J, Movat H Z. Neutrophil leukocyte emigration induced by endotoxin. Mediator roles of interleukin 1 and tumor necrosis factor a. 7 Immunol 1988; 140: 3144-9.

13 Rampart M, Williams T J. Evidence that neutrophil accumulation induced by interleukin-1 requires both local protein biosynthesis and neutrophil CD 18 antigen expression in biosynthesis and neutrophil CD 18 antigen
vivo. $\mathrm{Br} \mathrm{I}$ Pharmacol 1988; 94: 1143-8.

14 Movat $\mathrm{H} \mathrm{Z}$. Tumor necrosis factor and interleukin-1: role in acute inflammation and microvascular injury. $\mathcal{F}$ Lab Clin Med 1987; 110: 668-81.

15 Granstein R D, Margolis R, Mizel S B, Sauder D N. In vivo inflammatory activity of epidermal cell-derived thymocyte 
activating factor and recombinant interleukin 1 in the mouse. F Clin Invest 1986; 77: 1020-7.

16 Bevilacqua M P, Pober J S, Wheeler M E, Cotran R S Gimbrone $M$ A. Interleukin-1 activation of vascular endothelium. Effects on procoagulant activity and leukocyte adhesion. Am 7 Pathol 1985; 121: 393-403.

17 Bevilacqua M P, Pober J S, Wheeler M E, Cotran R S, Gimbrone $M$ A. Interleukin 1 acts on cultured human vascular endothelium to increase the adhesion of polymorphonuclear leukocytes, monocytes, and related leukocyte morphonuclear leukocytes, monocytes, and r

18 Cavender D, Haskard D, Foster N, Ziff M. Superinduction of T lymphocyte-endothelial (EC) binding by treatment of of T lymphocyte-endothelial (EC) binding by treatment of EC with interleukin 1 and prote

19 Cavender D, Haskard D, Foster N, Ziff M. Interleukin 1 increases the binding of human $B$ and $T$ lymphocytes to endothelial cell monolayers. F Immunol 1986; 136: 203-7.

$20 \mathrm{Ziff} M$. Role of cytokines in reumatoid synovitis. Medicina ( $B$ Aires) 1988; 79: 318-22.

21 Pettipher E R, Higgs G A, Henderson B. Interleukin 1 induces leukocyte infiltration and cartilage proteoglycan degradation in the synovial joiat. Proc Natl Acad Sci USA 1986; 83: 8749-53.

22 Stimpson S A, Dalldorf F G, Otterness I G, Schwab J H. Exacerbation of arthritis by IL-1 in rat joints previously
injured by peptidoglycan-polysaccharide. $\mathcal{F}$ Immunol 1988; injured by pe $2964-9$.

23 Wood D D, Ihrie E J, Hamerman D. Release of interleukin-1 from human synovial tissue in vitro. Arthritis Rheum 1985 28: 853-62.

24 Danis V A, March L M, Nelson D S, Brooks P M Interleukin-1 secretion by peripheral blood monocytes and synovial macrophages from patients with rheumatoid arthritis. F Rheumatol 1987; 14: 33-9.

25 Wood D D, Ihrie E J, Dinarello C A, Cohen P L. Isolation of an interleukin-1-like factor from human joint effusions. Arthritis Rheum 1983; 26: 975-83.

26 Miossec $\mathbf{P}$, Dinarello $C$, Ziff $M$. Interleukin-1 lymphocyte chemotactic activity in rheumatoid arthritis synovial fluid. Arthritis Rheum 1986; 29: 461-9.

27 Nouri A M E, Panayi G S, Goodman S M. Cytokines and the chronic inflammation of rheumatic disease. I. The presence of interleukin-1 in synovial fluids. Clin Exp Immunol 1984; 55: 295-302.

28 Bendtzen K, Petersen J, Halkjaer-Kristensen J, IngemannHansen T. Interleukin-1-like activities in synovial fluids of patients with rheumatoid arthritis and traumatic synovitis. Rheumatol Int 1985; 5: 79-82.

29 Hopkins S J, Humphreys M, Jayson M I V. Cytokines in synovial fluid. I. The presence of biologically active and immunoreactive IL-1. Clin Exp Immunol 1988; 72: 422-7.

30 Krakauer T, Oppenheim J J, Jasin H E. Human interleukin I mediates cartilage matrix degradation. Cell Immunol 1985; 91: $92-9$.

31 Dingle J T. The role of catabolin in the control of cartilage matrix integrity. $\mathcal{J}$ Rheumatol 1983; 10 (suppl 11): 38-42.

32 Saklatvala J. Interleukin 1: purification and biochemical aspects of its action on cartilage. $\mathcal{F}$ Rheumatol 1987; 14: $52-4$.

33 Ikebe T, Hirata $M$, Koga T. Human recombinant interleukin 1-mediated suppression of glycosaminoglycan synthesis in cultured rat costal chondrocytes. Biochem Biophys Res Commun 1986; 140: 386-91.

34 Ratcliffe A, Tyler J E, Hardingham T E. Articular cartilage cultured with interleukin 1 . Increased release of link protein, hyaluronate-binding region and other proteoglycan protein, hyaluronate-binding region and othe
fragments. Biochem $\mathcal{F}$ 1986; 238: 571-80.

35 Tyler J E. Articular cartilage cultured with catabolin (pig interleukin 1) synthesizes a decreased number of normal interleukin 1) synthesizes a decreased number of nor
proteoglycan molecules. Biochem $\mathcal{F}$ 1985; 227: 869-78.

36 Tyler J E. Chondrocyte-mediated depletion of articular cartilage proteoglycans in vitro. Biochem $\mathcal{f} 1985$; 225: 493-507.

37 van den Berg W B, van de Loo F A J, Zwarts W A, Otterness I G. Effects of murine recombinant interleukin 1 on intact homologous articular cartilage: a quantitative and autoradiograpinic study. Ann Rheum Dis 1988; 47: 855-63.

38 Gilman S C, Hodge T, Chang J. Articular synovitis in rat knee joints induced by interleukin 1 [Abstract]. Arthritis Rheum 1987; 30: 529 .
39 Dingle J T, Page Thomas D P, Hazleman B. The role of cytokines in arthritic diseases: in vitro and in vivo measurements of cartilage degradation. Int $\mathcal{F}$ Tissue React 1987; IX 349-54.

40 Dingle J T, Page Thomas D P, King B, Bard D R. In vivo studies of articular tissue damage mediated by catabolin interleukin 1. Ann Rheum Dis 1987; 46: 527-33

41 Pettipher E R, Henderson B, Moncada S, Higgs G A Leucocyte infiltration and cartilage proteoglycan loss in immune arthritis in the rabbit. Brf Pharmacol 1988; 95: immune 76.

42 Lens J W, van den Berg W B, van de Putte L B A. Quantitation of arthritis by ${ }^{9} \mathrm{~m}$ Tc-uptake measurements in the mouse knee-joint: correlation with histological joint inflammation scores. Agents Actions 1984; 14: 723-8.

43 De Vries B J, van den Berg W B, Vitters E, van de Putte L B A. Quantitation of glycosaminoglycan metabolism in anatomically intact articular cartilage of the mouse patella: in vitro and in vivo studies with ${ }^{35} \mathrm{~S}$-sulfate, ${ }^{3} \mathrm{H}$-glucosamine, and ${ }^{3} \mathrm{H}$-acetate. Rheumatol Int 1986; 6: 273-81.

44 Kruijsen $M$ W M, van den Berg W B, van de Putte L B A. Sequential alterations of periarticular structures in antigeninduced arthritis in mice. Histological observations on fibrous capsule, ligaments, bone and muscles, using whole fibrous capsule, ligaments, bone and muscles, using

45 Pouman T H, Stanness K A Beatty P G Ochs H D, Harlan $J M$. An endothelial cell surface factor(s) induced in vitro by lipopolysaccharide, interleukin 1 , and tumor necrosis factor- $\Omega$ increases neutrophil adherence by a CDw18 dependent mechanism. F Immunol 1986; 136: 4548-53.

46 Beck G, Habicht G S, Benach J L, Miller F. Interleukin 1: a common endogenous mediator of inflammation and the local Shwartzman reaction. 7 Immunol 1986; 136: 3025-31.

47 Movat H Z, Burrowes C E, Cybulsky M I, Dinarello C A Acute inflammation and Shwartzman-like reaction induced by interleukin-1 and tumor necrosis factor. Am $\mathcal{f}$ Pathol 1987; 129: 463-76.

48 van de chronic murine antigen induced arthritis with rIL-1. Arthritis Rheum 1988; 31: S16.

49 Hom J T, Bendele A M, Carlson D G. In vivo administration with IL-1 accelerates the development of collagen-induced arthritis in mice. $\mathcal{F}$ Immunol 1988; 141: 834-41.

50 Sedgwick A D, Moore A R, Al-Duaii A Y, Edwards J C W, Willoughby D A. Studies into the influence of carrageenaninduced inflammation on articular cartilage degradation using implantation into air pouches. Br $\mathcal{F}$ Exp Pathol 1985; 66: 445-53.

51 Tiku K, Tiku M L, Liu S, Skosey J L. Normal human neutrophils are a source of a specific interleukin 1 inhibitor. f Immunol 1986; 136: 3686-92.

52 Arend W P, Joslin F G, Massoni J. Effects of immune complexes on production by human monocytes of interleukin 1 or an interleukin 1 inhibitor. $\mathcal{f}$ Immunol 1985; 134: 3868-75.

53 Benton H P, Tyler J A. Inhibition of cartilage proteoglycan synthesis by interleukin 1. Biochem Biophys Res Commun 1988; 154: 421-8.

54 Gilman S C. Activation of rabbit articular chondrocytes by recombinant human cytokines. I Rheumatol 1987; 14: 1002-7.

55 Pasternak R D, Hubbs S J, Caccese R G, Marks R L, Conaty J M, Dipasquale G. Interleukin-1 stimulates the secretion of proteoglycan- and collagen-degrading proteases by rabbit articular chondrocytes. Clin Immunol Immunopathol 1986; 41: $351-67$.

56 Schnyder J, Payne T, Dinarello C A. Human monocyte or recombinant interleukin $1 \mathrm{~s}$ are specific for the secretion of a metalloproteinase from chondrocytes. F Immunol 1987; 138: 496-503.

57 Wood D D, Bayne E K, Goldring M B, et al. The four biochemically distinct species of human interleukin 1 all exhibit similar biologic activities. F Immunol 1985; 134: exhibit

58 Saklatvala J, Bird T. A common class of receptors for the two types of porcine interleukin-1 on articular chondrocytes. Lymphokine Res 1986; 5: S99-104.

59 Bird T A, Saklatvala J. Identification of a common class of high affinity receptors for both types of porcine interleukin1 on connective tissue cells. Nature 1986; 324: 263-5. 